ARGONNE NATIONAL LABORATORY

P. O. Box 299

Lemont, Illinois

\title{
THIOCYANATE SPECTROPHOTOMETRIC DETERMINATION OF MOLYBDENUM AND TUNGSTEN
}

by

C. E. Crouthamel and C. E. Johnson

Chemical Engineering Division

February 1954

Operated by The University of Chicago

under

Contract $W-31-109-e n g-38$ 


\section{DISCLAIMER}

This report was prepared as an account of work sponsored by an agency of the United States Government. Neither the United States Government nor any agency Thereof, nor any of their employees, makes any warranty, express or implied, or assumes any legal liability or responsibility for the accuracy, completeness, or usefulness of any information, apparatus, product, or process disclosed, or represents that its use would not infringe privately owned rights. Reference herein to any specific commercial product, process, or service by trade name, trademark, manufacturer, or otherwise does not necessarily constitute or imply its endorsement, recommendation, or favoring by the United States Government or any agency thereof. The views and opinions of authors expressed herein do not necessarily state or reflect those of the United States Government or any agency thereof. 


\section{DISCLAIMER}

Portions of this document may be illegible in electronic image products. Images are produced from the best available original document. 


\section{THIOCYANATE SPECTROPHOTOMETRIC DETERMINATION OF MOLYBDENUM AND TUNGSTEN \\ by}

C. E. Crouthamel and C. E. Johnson

I. Introduction

Thiocyanate has been employed fairly extensively in the spectrophotometric analysis of number of metal ions. The application of thiocy anate to the determination of cobalt $(1)$ and of iron $(2),(3)$ are two of the oldest colorimetric methods. The thiocyanate method has also been applied in the analysis of molybdenum, rhenium, tungsten, and more recently, uranium and niobium. The authors have studied the color development with thiocyanate in a homogeneous acetone-aqueous system for thirty elements. The results of a study of molybdenum and tungsten in Sub-group VI are reported here. Reports on groups IV, V, and VII are in preparation.

The choice of the acetone-aqueous system was based largely on the experience gained in previous work on uranium. (4) In general, acetone gave the highest sensitivity in homogeneous system, showed the greatest tendency to prevent interference from other anions, and showed a favorable general solubility for a wide variety of salts and acids. Stabilization of many valent states was more easily accomplished in acetone.

The authors believe that they have minimized the effect of previous history of the molybdenum and tungsten solutions on the color development. Some of the difficulties in color development caused by reactions kinetics, quantitative achievement of the proper valent state, and the presence of multiple species in a given valent state have been eliminated.

\section{I. Reagents}

Ammonium thiocyanate, C.P. reagent grade material, was recrys tallized from a saturated methanol solution. The methanol solution of ammonium thiocyanate was saturated at $50^{\circ} \mathrm{C}$. in a water bath and the warm solution filtered by drawing through a coarse porosity glass filter disc into a filter flask. Polythene tubing was used to connect the disc and flask. (Rubber tubing introduces organic materials which form colored products.) The saturated methanol solution was cooled in an ice bath, and the crystals were filtered on a coarse porosity glass filter disc. The crystals were dried thoroughly by means of dry air or nitrogen flowing rapidly through the crystalline mass for twenty-four hours. The crystals were broken and 
then were stored in a drying cylinder, through which passed a moderate flow of dried gas. A tube of anhydrous calcium sulfate was used to dry the air or nitrogen gas stream. At $25^{\circ} \mathrm{C}$. and a relative humidity of $10 \%$ or less, the crystals may be air -dried by spreading them on a clean, inert surface. At $25^{\circ} \mathrm{C}$. and a relative humidity greater than $50 \%$, however, the crystals appeared wet after 24 hours in the open air. The wet crystals invariably yielded poorer color stability, varying somewhat with the metal analyzed and the storage time and storage temperature. The importance of working with recrystallized and dry-stored ammonium thiocyanate crystals cannot be overemphasized if precise and uniform results are to be obtained.

Standard solutions of $W(V I)$ were prepared by weighing pure tungstic oxide or anhydrous sodium tungstate into $50 \mathrm{ml}$. of $0.25 \mathrm{M}$ sodium hydroxide. The sodium tungstate was then added slowly and with stirring to approximately $900 \mathrm{ml}$. of concentrated hydrochloric acid and diluted to volume with concentrated hydrochloric acid. Concentrations of W(VI) up to $0.006 \mathrm{M}$ were obtained and were stable over long periods.

Standard Mo(VI) was prepared by weighing and dissolving reagent grade molybdic oxide in a minimum of $8 \mathrm{M}$ hydrochloric acid.

\section{Apparatus}

A Beckman model DU quartz spectrophotometer and a Cary Model 11 recording spectrophotometer were both used. One-centimeter quartz cells were used throughout.

\section{Molybdenum}

The thiocyanate spectrophotometric method has long been considered one of the most reliable methods $(5)$ for the analysis of trace amounts of molybdenum. The development of the molybdenum thiocyanate complex and the extraction of the color into ether was applied 90 years ago(6) and more recently by King. (7) M. Kapron and P. L. Hehman (8) developed the molybdenum thiocyanate complex directly in butyl cellosolve and butyl carbitol aqueous mixtures. These investigators were using the Mo(v)-thiocyanate complex; the present authors also found this to be the most useful species.

A graphic summary of some of the molybdenum reactions in aqueous and acetone media is given in Figure 1. It should be emphasized that a detailed study of the kinetics of each of the various reactions was not under taken, and Figure 1 is limited mainly to information which the authors feel is essential to the intelligent application of the color developing procedures. It was found that only $\mathrm{Mo}(\mathrm{V})$ developed the characteristic colors which have previously been applied in the analysis of this element. Thus the major 

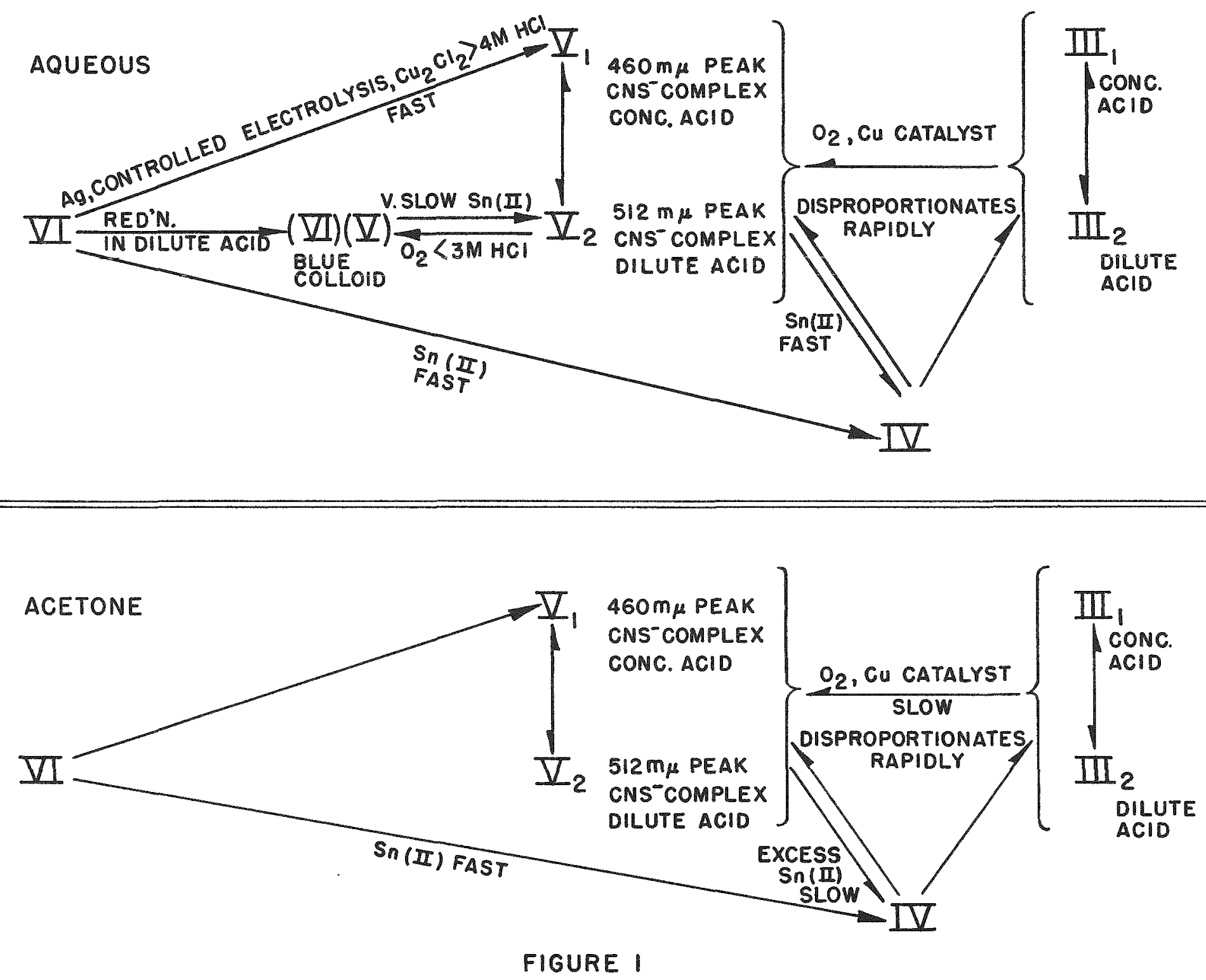

MOLYBDENUM REACTION SCHEME 
problem has been the quantitative reduction of Mo(VI) to Mo(V). A glance at Figure 1 will also give the reader a quick survey of most of the difficulties involved. It appears that previous methods have achieved only $50-75 \%$ of the maximum possible color intensity, and the major difficulty has been traced to the reduction reaction or stabilization of Mo(V) in solution. Even when observing the warning of A. T. Dick and J. B. Bingley (9) that iron or copperfree Mo(VI) solutions developed only $65 \%$ of the color when reduced with $\mathrm{Sn}(\mathrm{II})$, very slow and erratic color development will occur if the correct sequence of addition of reagents is not observed. Slow color development shown in Figure $Z$ occurred when $M o(V I)$ solution was first reduced with excess $\mathrm{SnCl}_{2}$ in acetone-aqueous medium, followed by the addition of $\mathrm{Cu}_{2} \mathrm{Cl}_{2}$. The absorbance in this case reached a maximum after standing about 60 min. A similar slow color development occurs in aqueous medium, or a lower color intensity is obtained when ether extracted. Rapid and quantitative development of the color was always achieved by first reducing Mo(VI) to $\mathrm{Mo}(\mathrm{V})$ with $\mathrm{Cu}(\mathrm{I})$ in $4 \mathrm{M}$ hydrochloric acid solution. In previous work, no attempt has been made to obtain the maximum molar absorbance index for standard molybdenum solutions in any given medium.

N. Birnbaum and G. H. Walden(10) have shown that stable standard $\mathrm{Mo}(\mathrm{V})$ solutions may be prepared by reduction of Mo(VI) in approximately $4 \mathrm{M}$ hydrochloric acid at $60^{\circ} \mathrm{C}$. in a silver reductor. The reduction was complete and the stoichiometry of the reaction checked by titration of the Mo(V) with standard ferric chloride. The thiocyanate complex developed an absorbance with the Mo(v) standard in aqueous, acetone, and ether media identical with that obtained by the Cu(I) reduction procedure on Mo(VI) standards in the three media, in both the complete form of the spectra and the intensity.

The color of the Mo(V)-thiocyanate complex shown in Figure 3 was ined directly upon the addition of 100-250 microliter aliquots of $\mathrm{Mo}(\mathrm{V})$ obta slutions to aqueous, acetone, or ether thiocyanate solutions. The stock si f a moderate excess of $\mathrm{Sn}$ (II) or $\mathrm{Sn}$ (II) and $\mathrm{Cu}$ (I) did not affect the addition 0 , tone or ether. A large excess of $\mathrm{Sn}$ (II), however, slowly recolor in ace (V) to reduce the absorbance. Additions of excess Sn(II) to artre with $\mathrm{Mc}$ 'ution reacted more readily with the $\mathrm{Mo}(\mathrm{V})$ to reduce the the aqueous sol $7 \mathrm{~s}$ been the source of previous analytical difficulties in this media.

A search for ev idence for mixed valent complexes and for possible reactions of Mo(V) with the acetone, ether or thiocyanate indicated none of these complications. The observed rate of color development in all the media was complete and stable within $20 \mathrm{sec}$, the time required for complete mixing, after introduction of the $M(V)$ into the various thiocyanate media and the filling of a dried quartz cell. Also a $50 \%$ decrease in the molar absorbance index was always obtained for the total molybdenum concentration when the color was developed in previously mixed equimolar 
FIGURE 2

EFFECT OF COPPER ON THE REDUCTION OF MOLYBDENUM WITH STANNOUS CHLORIDE.

MOLYBDENUM INITIALLY IN HEXAVALENT STATE, $8.10 \times 10^{-5} \mathrm{M}$ 60 VOLUME PERCENT ACETONE AND $0.6 \mathrm{M} \mathrm{NH}_{4}$ CNS

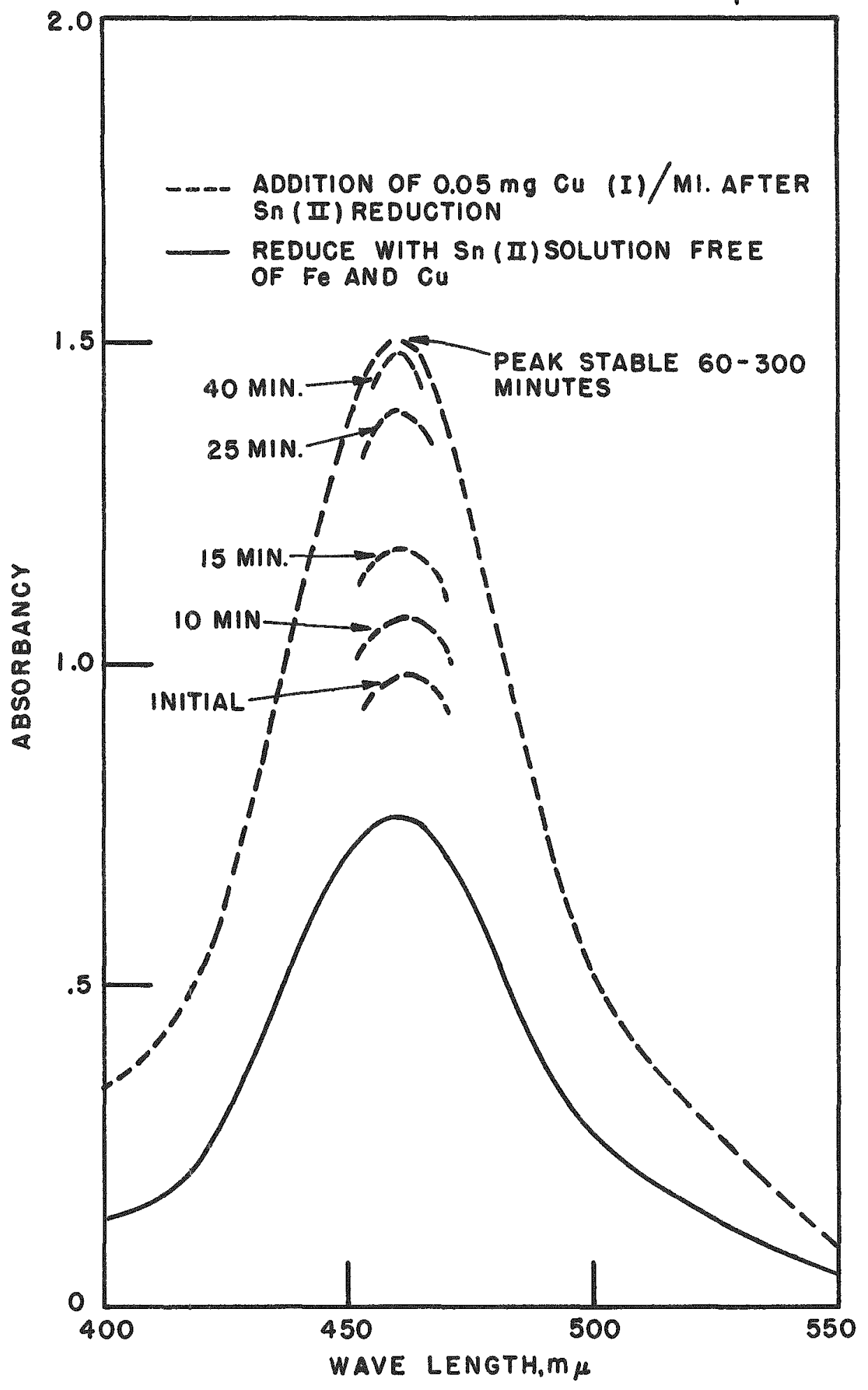


FIGURE 3

COMPARISON OF MO (II) THIOCYANATE COMPLEX DEVELOPED IN VARIOUS MEDIA

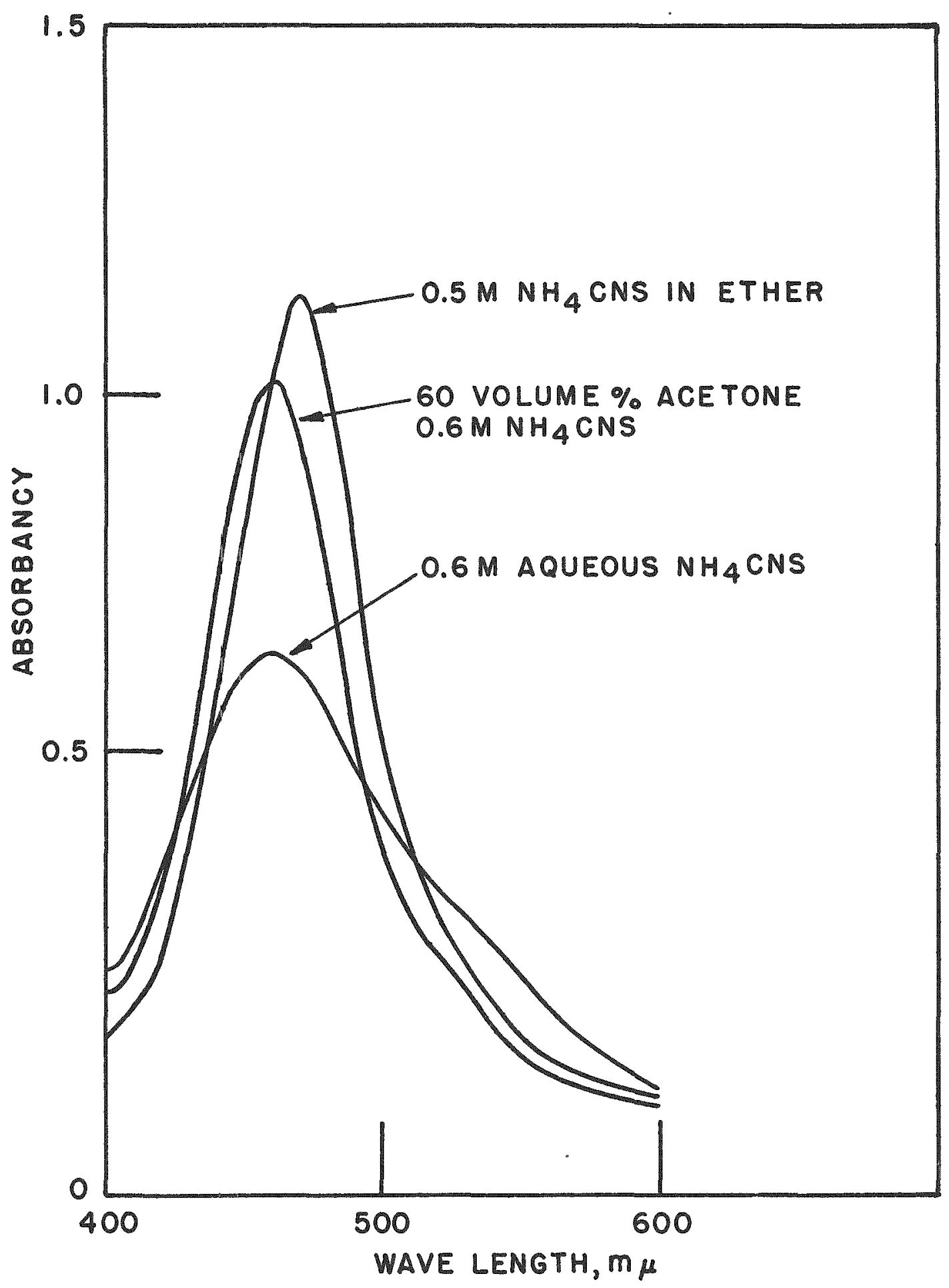


mixtures of $M o(V I)$ and $M o(V)$ and $M o(V)$ and $M o(I I)$. Mo(III) was prepared by reduction of a concentrated hydrochloric acid solution of Mo(VI) with granulated lead in an inert atmosphere. The solution of Mo(III) in $\geq 10 \mathrm{M}$ hydrochloric acid was red. The absorbance index also decreased when $\mathrm{Mo}(V)$ was partially oxidized $\left(\mathrm{Br}_{2}\right)$ or reduced $(\mathrm{Sn}(\mathrm{II}))$ in the presence of thiocyanate. The authors have concluded, therefore, that the $460 \mathrm{~m} \mu$ and $470 \mathrm{~m} \mu$ absorbance peaks shown in Figure 3 are due only to a Mo(v) thiocy anate complex and represent the maximum obtainable molar absorbance index in the media described.

Figure 4 shows the effect of thiocyanate and hydrochloric acid concentration in the acetone medium on the molar absorbance index. For the acetone-aqueous medium (60 volume \% acetone) and $0.6 \mathrm{M}$ ammonium thiocyanate the molar absorbance index and the standard deviation at the $460 \mathrm{~m} \mu$ maximum was 18,700 150 . Figure 5 shows the obedience of the total molybdenum concentration to Beer's Law. The ether extraction procedure gave a molar absorbance index and standard deviation at the $470 \mathrm{~m} \mu$ maximum of $19,500 \div 200$.

It is now possible to employ the molar absorbance index obtained with the standard Mo(V) solution to explain the remarkable effects observed with copper and iron in developing the Mo(V) thiocyanate complex. It was shown in Figure 2 that iron-and copper-free solutions of molybdenum developed only $50 \%$ of the maximum colox when reduced with moderate excess of $\mathrm{Sn}(\mathrm{II})$. The $50 \%$ color development was more easily demonstrated at the higher molybdenum concentrations in the acetone thiocyanate medium. In ordinary work where traces ( $>1$ p.p.m.) of iron or copper were present, the color intensity ranged between $50-75 \%$ of the known maximum. In each of these low intensity color developments the scanned $460 \mathrm{~m} \mu$ absorbance peak showed no changes in form anywhere in the visible region $(800-300 \mathrm{~m} \mu)$.

The following explanation is consistent with all the observed facts and aiso allows one to hypothesize a reaction scheme. to Mo(IV):

Reaction (1) shows the rapid direct two-electron reduction of Mo(VI)

$$
\mathrm{Mo}(\mathrm{VI})+\mathrm{Sn}(\mathrm{II}) \stackrel{\mathrm{rapid}}{\longrightarrow} \mathrm{Mo}(\mathrm{IV})+\mathrm{Sn}(\mathrm{VI})
$$

Y is assumed that this is rapidly followed by reaction (2):

$$
2 \mathrm{Mo}(\mathrm{IV}) \longrightarrow \mathrm{Mo}(\mathrm{V})+\mathrm{Mo}(\mathrm{III})
$$

It must be assumed that $\mathrm{M}(\mathrm{VI})$ is depleted quickly and/or no appreciable reaction with Mo(III) occurs. 


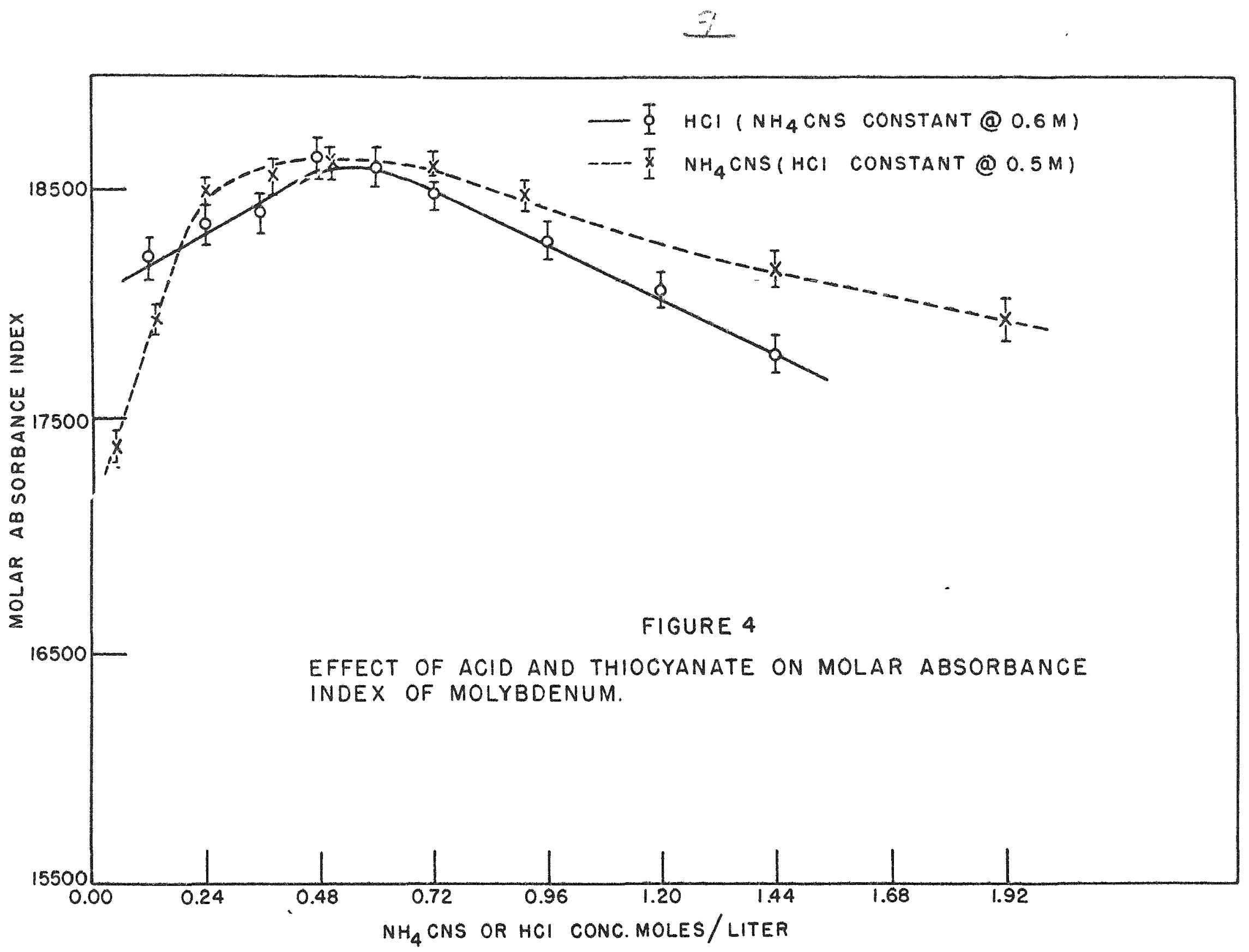




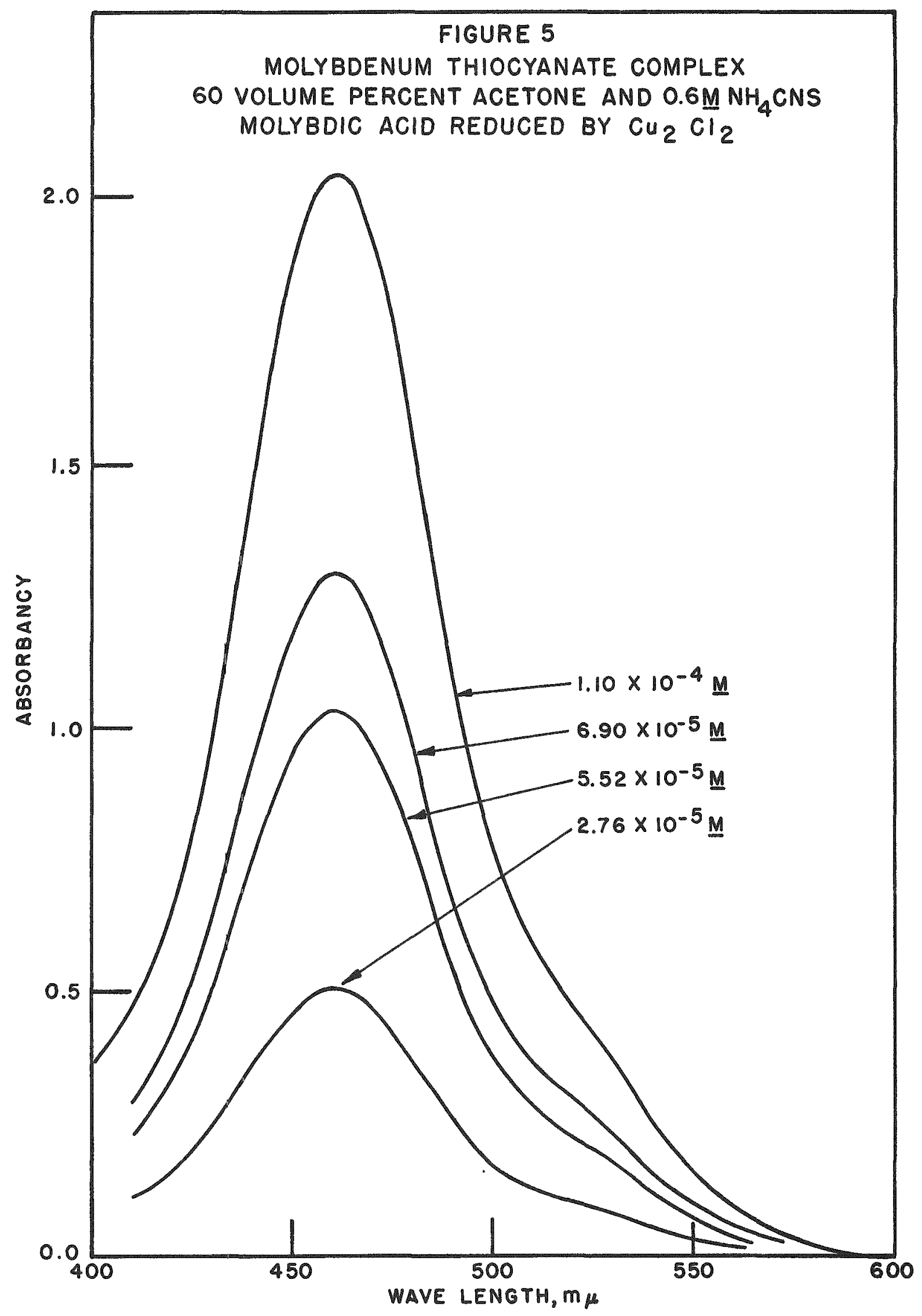


It was shown independently, firstly, that mixtures of $\mathrm{Mo}(\mathrm{V})$ and Mo(III) do not react to form a mixed valent complex, and, secondly, that moderate excess of $\mathrm{Sn}(\mathrm{II})$ will not reduce $\mathrm{Mo}(\mathrm{V})$ in the acetone thiocyanate medium. The half color intensity solutions were quite stable in the absence of copper or iron. If the above explanation is right the correct reduction procedure may be immediately prescribed.

A relatively weak and preferably soluble one-electron reducing agent capable of only the step, Mo(VI) to $\mathrm{Mo}(\mathrm{V})$, is required. Thus, the reduction of Mo(VI) with $\mathrm{Cu}(\mathrm{I})$ as recommended in the standard procedure did give the maximum molar absorbance index. In this procedure, $S n$ (II) was added to reduce the $\mathrm{Cu}(\mathrm{II})$ or $\mathrm{Fe}$ (III) only after the $\mathrm{Mo}(\mathrm{V})$ was formed and complexed in the thiocyanate acetone medium. Another possible method of developing the maximum color based on reactions (I) and (2) is to first reduce Mo(VI) quantitatively to $\mathrm{Mo}$ (III). In chloride medium $(>3 \mathrm{M} \mathrm{HCl})$, reactions (1) and (2) are followed by

$$
\mathrm{Mo}(\mathrm{V})+\mathrm{Sn}(\mathrm{II}) \longrightarrow \mathrm{Mo}(\mathrm{III}) \text { or } \mathrm{Mo}(\mathrm{IV})
$$

which in either case quantitatively reduces the Mo(VI) to Mo(III). Addition of the thiocyanate acetone reagent developed no appreciable color with Mo(III). However, if the excess of $\mathrm{Sn}$ (II) was relatively small, the addition of a trace of copper slowly developed the known maximum color, as shown in Figure 2. The removal of oxygen by saturating the solutions with carbon dioxide stopped the color development. Mo(III) with no Sn(II) present (prepared with lead reductor or by electrolysis) produced the correct maximum color when oxidized in either aqueous or acetone thiocyanate with a small excess of $\mathrm{Cu}(\mathrm{II})$. As in the standard procedure, the Cu(II) interference was finally removed with $S n$ (II) after Mo(V) thiocyanate complex was formed in the acetone medium. Although the silver reductor and controlled electrolysis may be employed to produce $\mathrm{Mo}(\mathrm{V})$ quantitatively, these methods of reduction are not readily adaptable to spectrophotometric work.

When starting with $\mathrm{Mo}(\mathrm{VI})$ solutions, there appeared to be very little difficulty with complex hydrolytic or polymeric unreactive species. In a 6-month period storage of stock solutions of Mo(VI) in neutral, alkaline, or strong acid $\left(>0.5 \mathrm{M} \mathrm{HCl}\right.$ or $\left.\mathrm{H}_{2} \mathrm{SO}_{4}\right)$ media did not reveal any difficulties with the color developing procedure. Solutions stored in dilute acid appeared to be easily reversible to a more reactive state by neutralizing or by warming slightly in concentrated hydrochloric acid. In genera1, molybdenum solutions caused considerably less difficulty than tungsten. In dilute acid, $(<0.25 \mathrm{M}$ ) either in aqueous ó acetone media, Mo(V) initially formed a $x$ ed thiocy ana te complex which s low ly transferred to the more stable species. Figure 6 shows a spectrophotometric record of such a reaction in $0.12 \mathrm{Mhydrochloric}$ acid. The $r e d \mathrm{Mo}(\mathrm{V})$ thiocyanate complex has a maximum absorbance at $512 \mathrm{~m} \mu$, and the orange Mo(V) thiocyanate complex absorbance maximum is a $460 \mathrm{~m} \mu$. The isobestic point of the 2 species is at $492 \mathrm{~m} \mu$. The standard Mo(v) stock solution used in the 


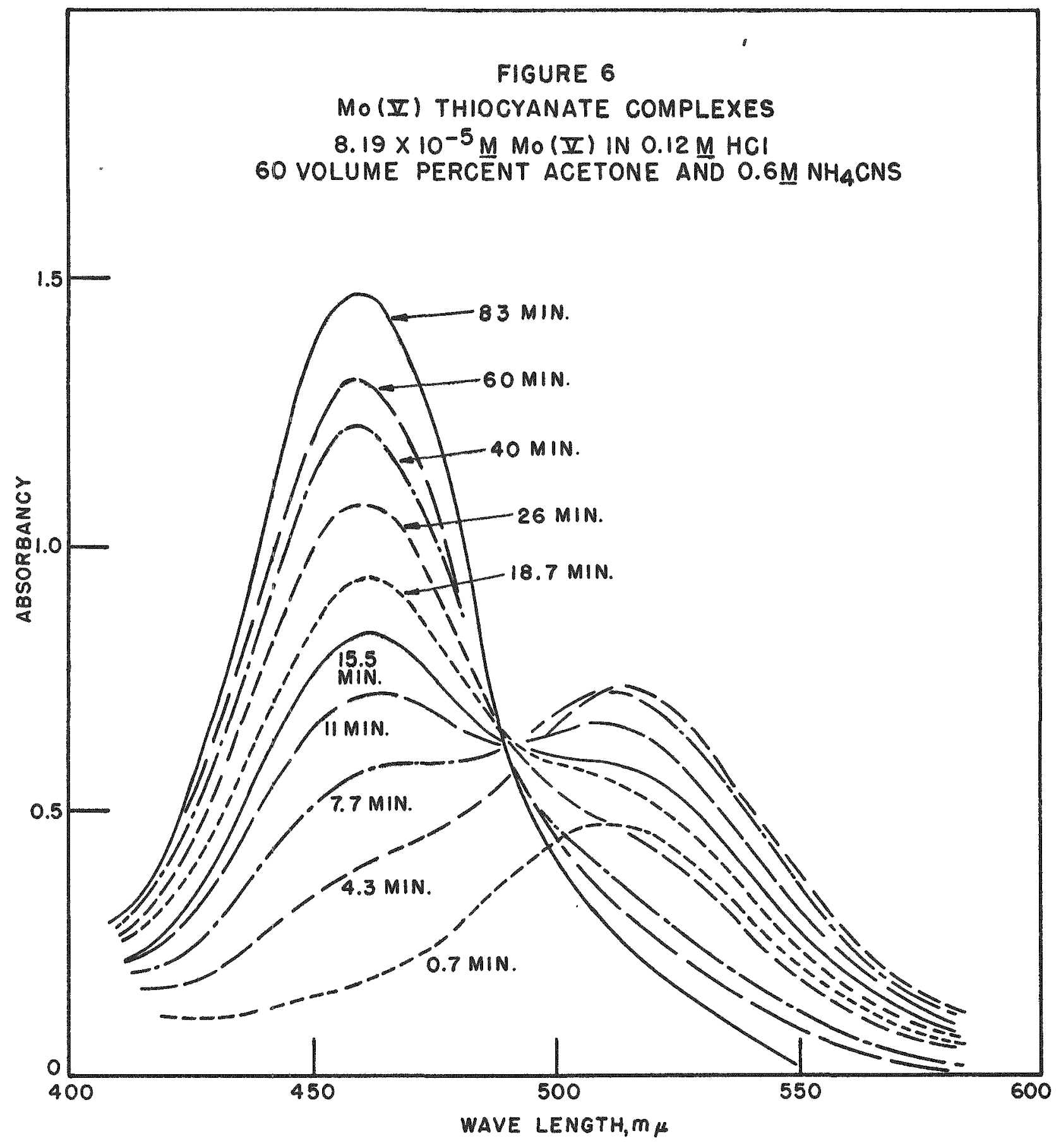


work of Figure 6 was prepared by reduction in a silver reductor according to the procedure of N. Birnbaum and $G$. H. Walden. $(10)$ The 0.7 min. and the $4.3 \mathrm{~min}$. curves of Figure 6 show the development of both species, and the $7.7 \mathrm{~min}$. curve shows the end of the development of the $512 \mathrm{~m} \mu$ species; the continued transference to the more stable $460 \mathrm{~m} \mu$ peak is shown in the remaining curves.

Color development in aqueous thiocyanate solutions was found to be highly unsatisfactory. The quantitative reduction of $\mathrm{Mo}(\mathrm{VI})$ to $\mathrm{Mo}(\mathrm{V})$ was very difficult to control. In dilute acids ( $1-4$ molar), the reduction of $\mathrm{Mo}$ (VI) to $\mathrm{Mo}(\mathrm{V})$ tended to produce the mixed valent Mo(VI) Mo(V) colloidal blue complexes. The quantitative reduction of this complexed Mo(VI) to $M o(V)$ is very slow and difficult. Also, the Mo(V) in the molybdenum blue complex does not readily form the characteristic Mo(V) thiocyanate complexes. It is important, therefore, not to attempt to reduce $M o(V I)$ to $M o(V)$ in less than approximately 8.0 $\mathrm{M}$ acid. After complete reduction to $\mathrm{Mo}(\mathrm{V})$ is accomplished, the solution may be diluted with water, and no immediate formation of molybdenum blue complex occurs, Dilute acid $(<8.0 \mathrm{MHCl})$ solutions of $\mathrm{Mo}(\mathrm{V})$ become increas ingly more sensitive to air oxidation. Molybdenum blue is the stable product formed. Mo(v) in 10-12 M hydrochloric acid is green, quite stable, and capable of storage for several weeks in air before a noticeable amount of oxidation occurs. In dilute hydrochloric acid, $\mathrm{Mo}(\mathrm{V})$ is brown and quite sensitive to air oxidation. However, it was noted that freshly prepared Mo(V) brown chloro complex did not delay the quantitative formation of the $460 \mathrm{~m} \mu \mathrm{Mo}(\mathrm{V})$ thiocy anate complex in the acetone medium if the final acid concentration was $>0.6 \mathrm{M}$. Aged in an inert atmosphere, brown Mo(V) showed an increasing tendency to form initially the red thiocyanate complex, which transfer $x$ ed as shown in Figure 6 , if adequate acid was present, to the $460 \mathrm{~m} \mu$ species.

V. Standard Procedures for Molybdenum

\section{A. Homogeneous Acetone Thiocyanate Method}

The solution of the sample may be effected in sulfuric or hydrochloric acid. If the sulfuric acid is reduced to approximately $1.0 \mathrm{ml}$. or less by fuming, no interference in the color development in a $25 \mathrm{ml}$. volume is experienced. To avoid the small exrors indicated in Figure 4 the acid concentration of the samples should be consistent with those of the standards. The acid concentration, however, should not be less than that required to make the final solution of $25 \mathrm{ml}$. about $0.3 \mathrm{M}$ and should not exceed $1.0 \mathrm{M}$, which would cause phase separation in the final acetone solution. Cuprous reduction of $\mathrm{Mo}(\mathrm{VI})$ becomes slow in less than $4 \mathrm{M}$ hydrochloric acid medium. Add 5 drops of 0.1 M cuprous chloride solution in concentrated hydrochloric acid. This solution is preparedas needed by adding drop-wise $10 \%$ by weight stannous chloride in concentrated hydrochloric acid to cupric chloride, leaving a slight excess of cupric chloride. The latter can be detected by its 
green color in concentrated hydrochloric acid medium. Dilute the solution containing the molybdenum and cuprous chloride with a few ml. of water, and add $15 \mathrm{ml}$, of $1.0 \mathrm{M}$ ammonium thiocyanate in acetone. Mix the solution and dilute with water, allowing for the addition of 5 drops of a $10 \%$ by weight solution of stannous chloride before finally diluting to $25 \mathrm{ml}$. with water and shaking. The correct color is developed rapidly, and the absorbance at $460 \mathrm{~m} \mu$ may be read immediately upon mixing the solution.

\section{B. Ether Thiocyanate Extraction Method}

One ml. of $0.1 \mathrm{M}$ cuprous chloride in concentrated hydrochloric acid was added to the Mo(VI) in approximately $8.0 \mathrm{M}$ hydrochloric acid. The volume in normal operation was limited to $3.0 \mathrm{ml}$. Molybdenum can be $x$ eadily oxidized to Mo(VI) by bromine and the excess removed by boiling. The Mo(V) thiocyanate complex was then formed by adding $3.0 \mathrm{ml}$. of $3.00 \mathrm{M}$ ammonium thiocyanate aqueous solution. Two $10 \mathrm{ml}$. portions of di-ethyl ether were used to extract the molybdenum and the extracts combined and diluted with ether to a $25 \mathrm{ml}$. volume. The absorbance maximum was at $470 \mathrm{~m} \mu$ and the molar absorbance index was 19,500 . The stability was not as good as the acetone solution. The absorbance should be obtained within a few minutes after extracting, as there was a slow decrease in color.

\section{Aqueous Molybdenum Thiocyanate Method}

This method is not recommended because of the difficulty in quantitatively obtaining the +5 valence state in solution and the marked decrease in sensitivity.

VI. Tungsten

The literature on the development of tungsten-thiocyanate methods has been compiled in previous works. (11),(12), (13) Gentry and Sherrington (13) made the reduction of $W(V I)$ to $W(V)$ prior to the addition of the thiocyanate and reported improved color stability. Freund, Wright, and Brookshier $(12)$ have studied the effect of the chloride ion and hydrogen ion concentration on the reduction of tungsten with stannous chloride. A minimum of $8 \mathrm{M}$ chloride ion and $10 \mathrm{M}$ total acid concentration used in this work is in essential agreement with the studies cited above.

One feature of the tungsten thiocyanate complex system was the relatively small effect obtained by employing acetone or ether to develop the color. This is shown in Figure 7. The peaks are sharper and higher in acetone and ether media. However, the effect is small compared to the more strongly hydrated niobium, titanium, vanadium, cobalt, and molybdenum species. The tungsten thiocyanate complex color was also relatively unaf fected by other complexing agents in the aqueous medium. Tartrate, citrate, 
FIGURE 7

COMPARISON OF W(II) THIOCYANATE ABSORBANCE DEVELOPED IN VARIOUS MEDIA $W$ (II) CONCENTRATION $6.15 \times 10^{-5} \mathrm{M}$

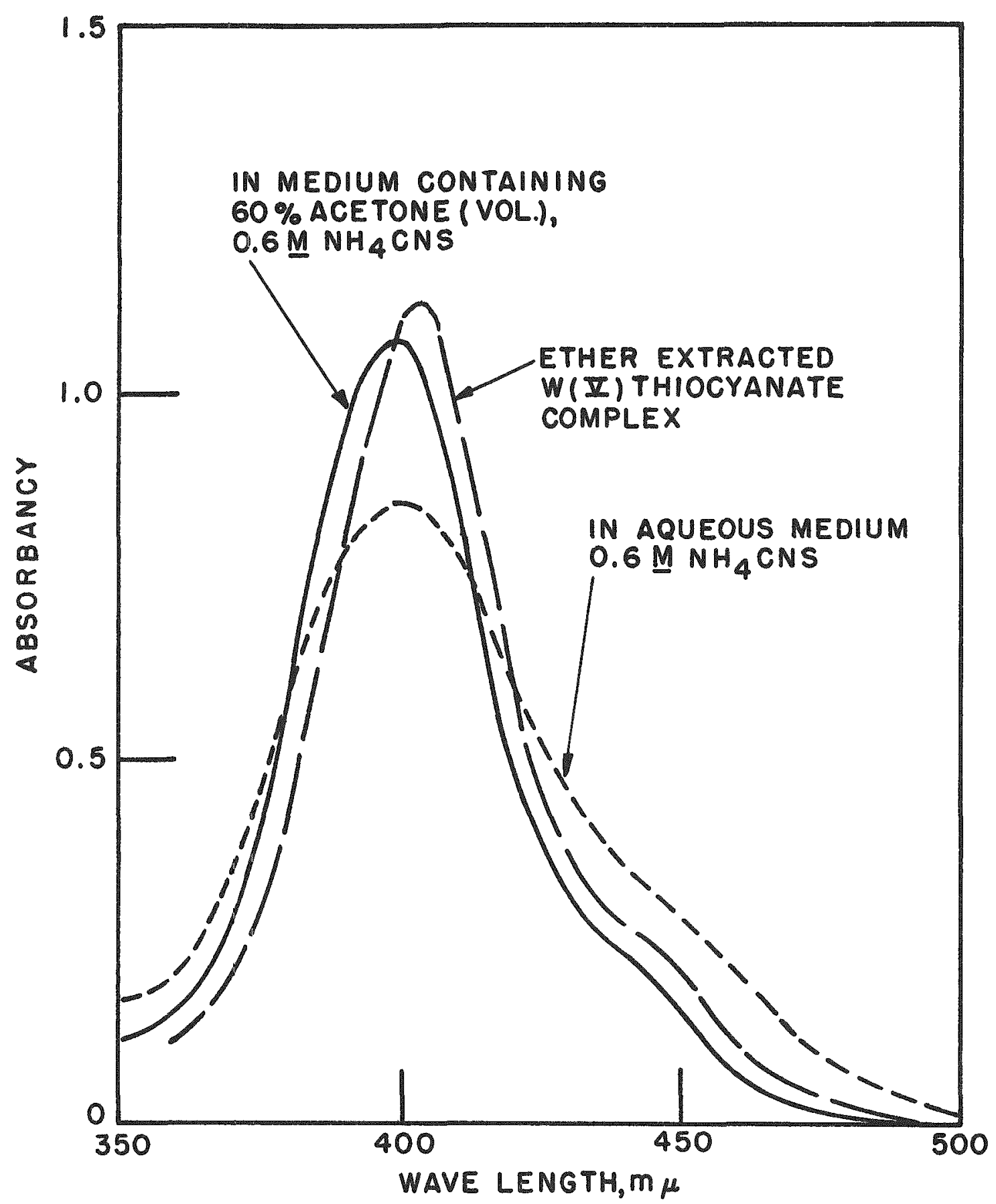


oxalate, and sulfate were without effect(13) in the aqueous medium at relatively high concentrations. This and the fact that the tungsten reaches a maximum absorbance in aqueous solution at the low thiocyanate concentration of $0.500 \mathrm{M}$ indicate that the complex formed must be relatively stable. Increased thiocyanate concentration tended to decrease the absorbance obtained, as was also found in the case of molybdenum.

The development of the tungsten color in aqueous medium is free of interference from niobium and titanium, which require acetone to develop any color. Older studies $(11),(13)$ have confused the facts on niobium interference in the tungsten method. Firstly, niobium does not develop a color with thiocyanate in aqueous medium, but readily does so in non-aqueous media.(14);(15) secondly, $\mathrm{Nb}(\mathrm{V})$ and not $\mathrm{Nb}(\mathrm{II})$ develops the yellow color with a maximum absorbance at $383 \mathrm{~m} \mu$. Also $\mathrm{Nb}(\mathrm{V})$ is not reduced to $\mathrm{Nb}$ (III) with tin metal, tin amalgams, or hot stannous chloride in strong hydrochloric or sulfuric acids.

Figure 8 shows the tungsten thiocyanate spectra obtained in acetone medium on concentrations varying by a factor of ten. Beer's Law was also obeyed by the total tungsten concentration in aqueous media in the concentration region tested (maximum $1.23 \times 10^{-4} \mathrm{M} / \mathrm{liter}$ tungsten). More than 20 experiments gave a molar absorbance index and standard deviation of 17,600 \pm 130 at $398 \mathrm{~m} \mu$.

Some of the pertinent reactions of tungsten in aqueous medium are summarized in Figure 9 . The reactions in acetone are more sluggish or do not proceed at appreciable rates. Oxidation of $W$ (III), however, to $75 \%$ $W(V)$ proceeds rapidly in both media. The importance of reducing W(VI) in a strong acid medium $(>10 \mathrm{M})$ to $W(V)$ cannot be over-emphasized. The formation of tungsten blue causes the color development to be slow and generally erratically low. Tungsten blue forms at much higher acidities than molybdenum blue and is thus much more troublesome. The intense blue color formation on reduction should serve as a warning to the analyst that trouble will follow in color development. The blue species is a mixed valent $W(V I)-W(V)$ compound, and is formed during reduction in solutions below approximately 9.0 molar in acidity. Dilution of either $W(V I)$ or $W(V)$ solutions alone with water produces no blue product, but dilution of the strong acid mixed valent solutions produces an immediate blue color. A second difficulty which has not been recognized as a separate problem is the existence of 2 forms of $W(V)$ as observed in the presence of thiocyanate, apparently analogous to the Mo(V) species (Figures 6 and 10 ). However, the $W(V)$ species cannot be quantitatively separated as in the case of the two Mo(V) forms (see Wigure 10). The transition of the $W(V)$ species also occurs at much higher acidity than the corresponding Mo(V) forms. 


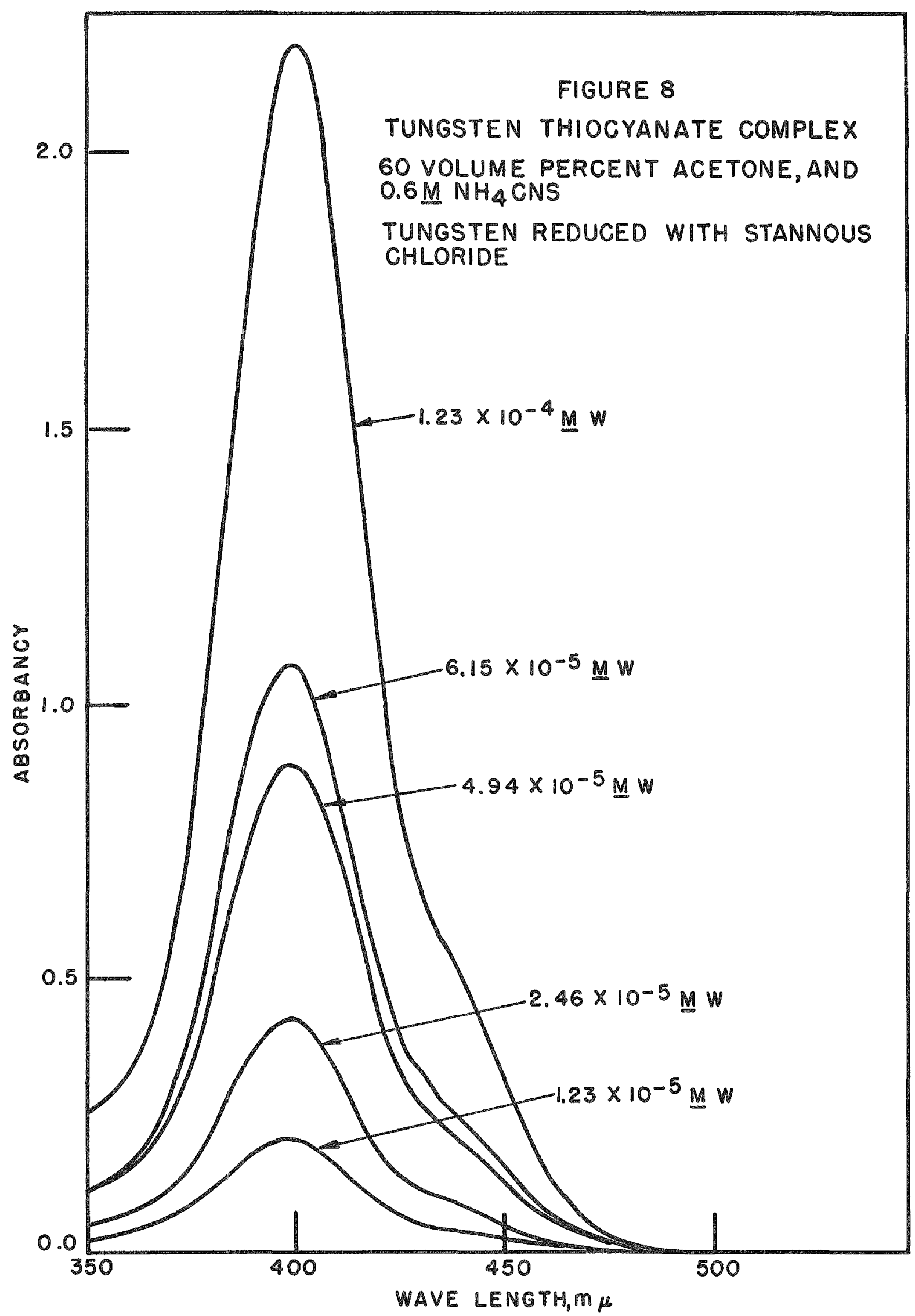




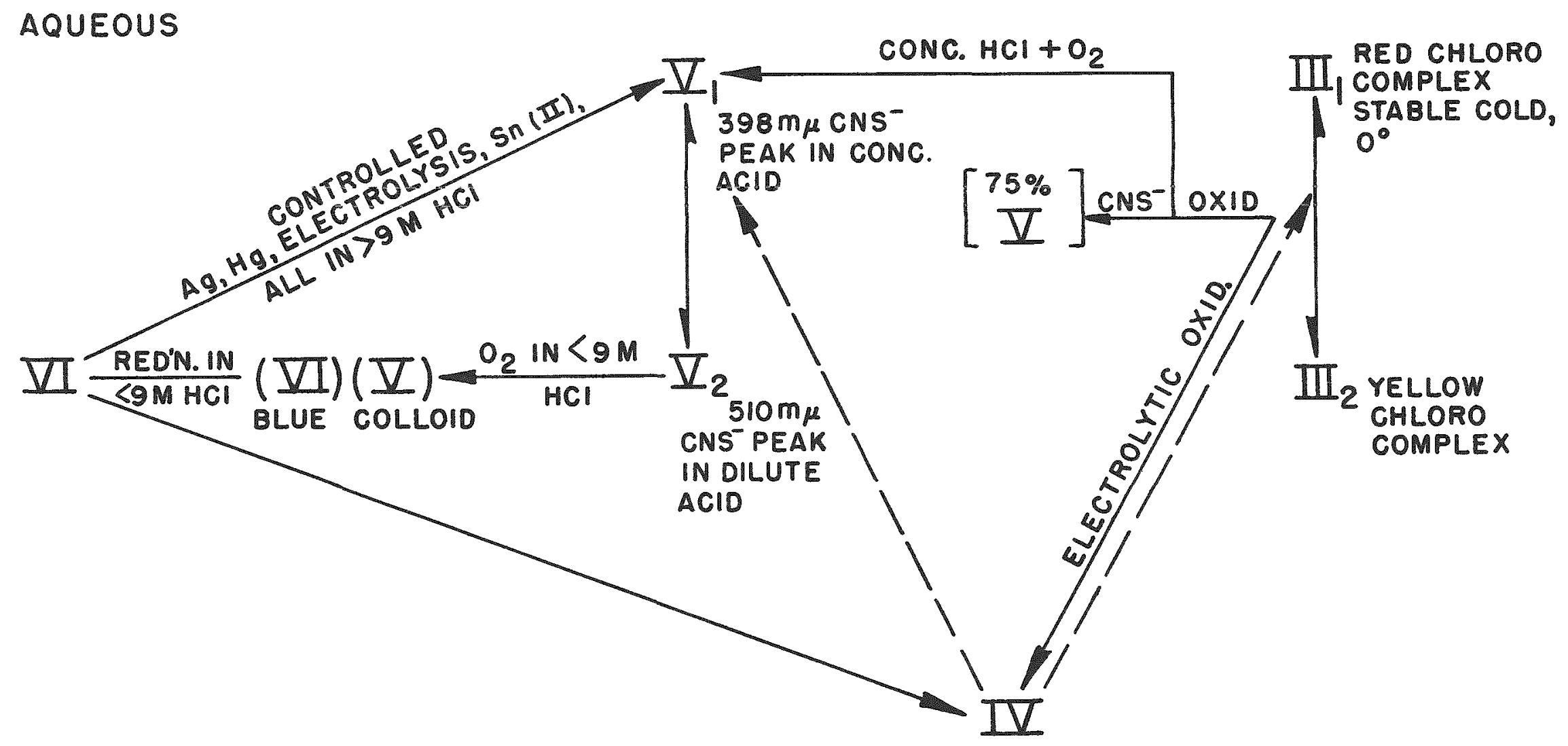

FIGURE 9

TUNGSTEN REACTION SCHEME 


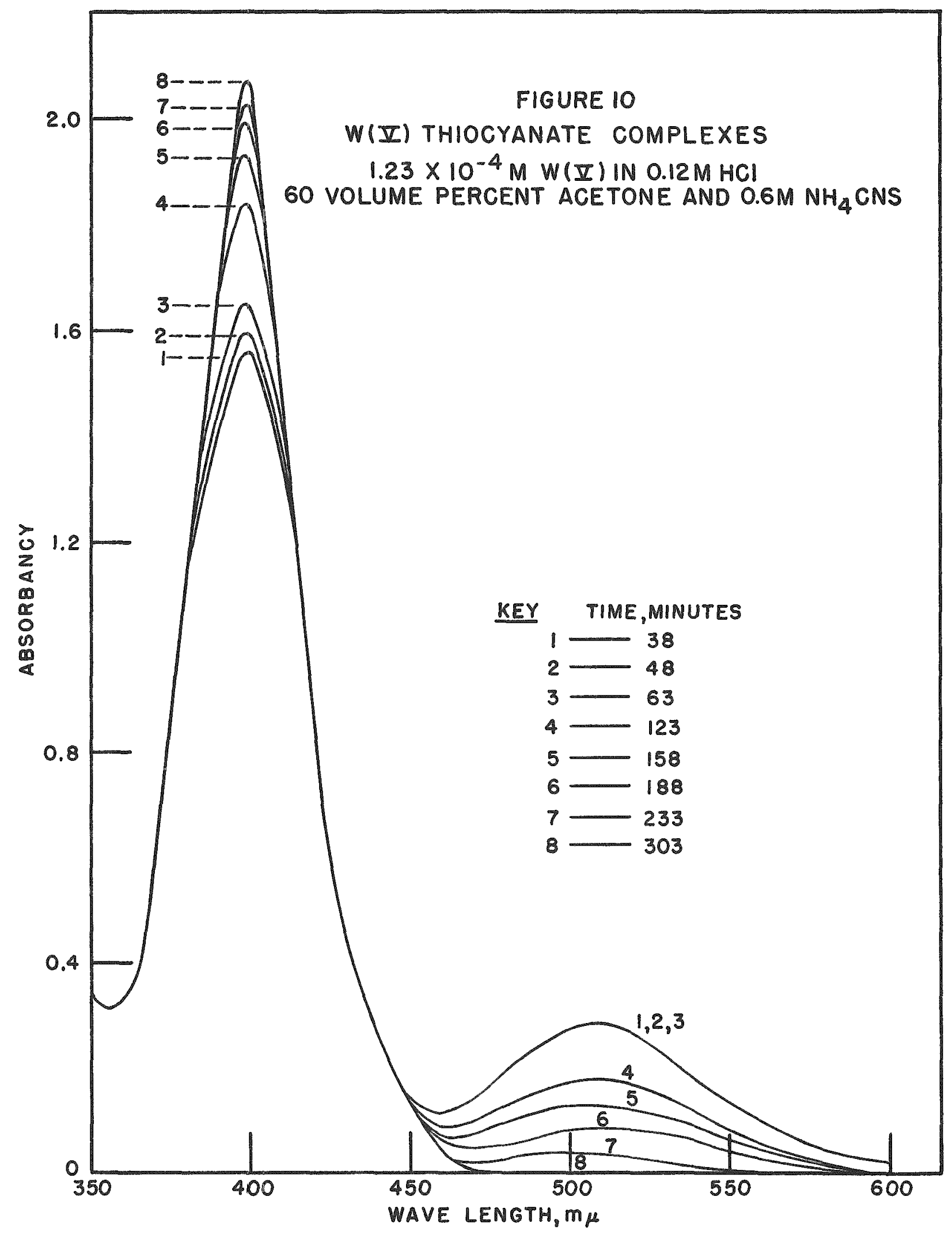


The analytically important features are the following. If the W(VI) is reduced in dilute acid ( $<9.0 \mathrm{M}$ HCl), a mixed valent tungsten blue forms which is unreactive with thiocyanate. Second, if the analyst quantitativcly reduces $W(V I)$ in strong acid to colorless or light blue $W(V)$ and then dilutes the acid solution with water $(<6.0 \mathrm{M} \mathrm{HCl})$, a yellow chloro complex of $W(V)$ is formed immediately. No tungsten blue is formed unles $W(V I)$ is present. Addition of thiocyanate to the yellow $\mathrm{W}(\mathrm{V})$ chloro complex in $6.0 \mathrm{M}$ hydrochloric acid develops an initial absorbance peak at $510 \mathrm{~m} \mu$ followed by its slow transfer to the $398 \mathrm{~m} \mu$ complex, as shown in Figure 10 . The time of color development increases with the amount of dilution, aging time after dilution, and the thiocyanate concentration. A third fact which has not been considered is the existence of several stable molar absorbance indexes for the $W(V) 398 \mathrm{~m} \mu$ absorbance peak. Thus, if thiocyanate is added to $W$ (III) in the red or yellow species, exactly $75 \%$ is oxidized by thiocyanate to $W(V)$, and the molar absorbance index is stabilized (see Figure 11). If W(VI) solution is reduced electrolytically, by shaking with mercury metal, by a silver reductor at $80^{\circ} \mathrm{C}$, or by $\mathrm{Sn}(\mathrm{II})$, all in concentrated hydrochloric acid medium, the color developed is the maximum intensity. In each case, the fractional and maximum spectra are identical except for the intensity. The maximum intensity as obtained by the 4 methods above is a molar absorbance index of 17,600 at the $398 \mathrm{~m} \mu$ peak. Quantitative reduction to W(III) red species was accomplished in each case at $0^{\circ} \mathrm{C}$. in concentrated hydrochloric acid by electrolysis at a mercury cathode, by tin metal, and by lead metal in nitro. gen atmosphere. The yellow species of W(III) formed rapidly from the red form at room temperature. The addition of the thiocyanate acetone medium to either the yellow or red W(III) species developed a stable W(V) thiocyanate absorbance spectra which was $75 \%$ of the known maximum. As shown in Figure 11, the color was formed on both yellow and red W(III) in approximately 15 min. The presence of excess $\mathrm{Sn}$ (II) in the acetone-thiocyanate medium did not affect the rate or per cent of the color formed.

VII. Standard Procedures for Tungsten

\section{A. Homogeneous Acetone Thiocyanate Method}

The W(VI) solution must be adjusted before reduction to $\geq 8 \mathrm{M}$ chloride ion concentration and $\geq 10 \mathrm{M}$ total acid. It has been found convenient to fume $W(\mathrm{VI})$ samples to a $0.5 \mathrm{ml}$. volume of concentrated sulfuric acid. No precipitation of tungstic acid occurs at the low concentrations of W(VI) required for color development. In one-centimeter cells, 10.5 micrograms of tungsten per $\mathrm{ml}$. developed unit absorbance. The additional chloride and acid was then added as $2 \mathrm{ml}$. of $10 \% \mathrm{SnCl}_{2}$ dissolved in concentrated hydrochloric acid. An alternative method of reduction was made by adding $0.1 \mathrm{ml}$. of mercury metal and $2 \mathrm{ml}$. of concentrated hydrochloric acid. The total volume during reduction was limited to $3 \mathrm{ml}$. or less. The reduction was made at room temperature for $30 \mathrm{~min}$. for both $\mathrm{Sn}$ (II) and mercury. Reduction time with mercury is a function of the mercury particle size during 
FIGURE II

EFFECT OF INITIAL VALENCE STATE ON FORMATION OF TUNGSTEN (II) THIOCYANATE COMPLEX

$$
1.10 \times 10^{-4} \mathrm{M} \text { TUNGSTEN }
$$

a) W(III) RED CHLORO COMPLEX

b) W(ZI) BLUE CHLORO COMPLEX

60 VOLUME PERCENT ACETONE, AND $0.6 \mathrm{M} \mathrm{NH}_{4} \mathrm{CNS}$

ABSORBANCY MEASURED AT $398 \mathrm{~m} \mu$

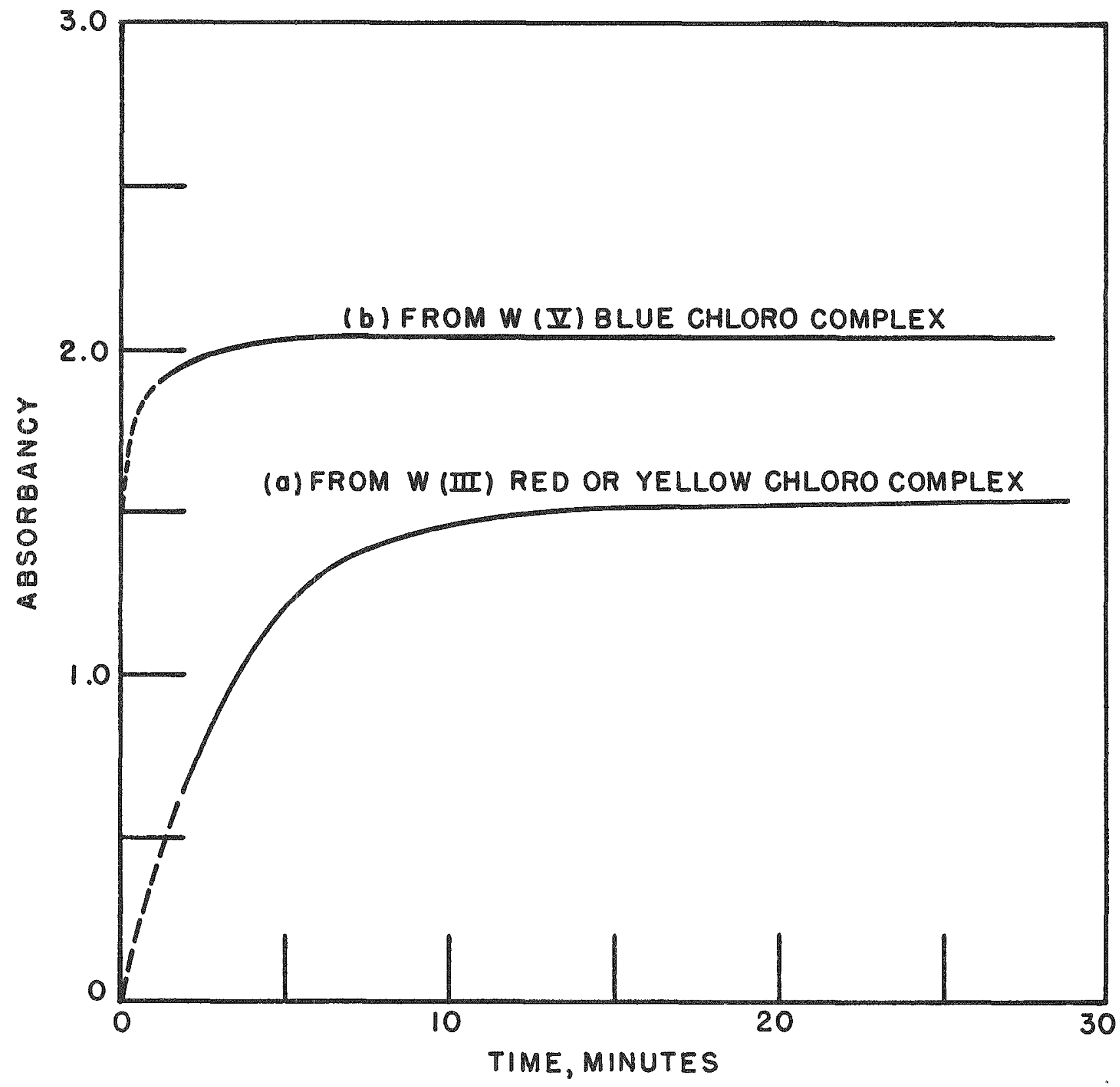


shaking. A Burrell wrist action shaker was employed in the tests made in this Laboratory. The color was then developed by adding $15 \mathrm{ml}$. of $1.0 \mathrm{M}$ am monium thiocyanate dissolved in acetone. The solution was diluted to $25 \mathrm{ml}$. with water. In cases where mercury was employed, the volume was corrected. Fifteen min. was allowed for the maximum color to develop. The absorbance maximum is at $398 \mathrm{~m} \mu$.

\section{B. Ether Thiocyanate Extraction Method}

The same procedure is used in reducing the tungsten to the pentavalent state. Five $\mathrm{ml}$. of 3.0 molar aqueous ammonium thiocyanate was added to the sample and extracted with two $10 \mathrm{ml}$. volumes of di-ethyl ether. The extracts were combined and diluted to $25 \mathrm{ml}$. with ether. The molar absorbance index is 18,300 at the $405 \mathrm{~m} \mu$ peak. The color should be read immediately.

\section{Aqueous Thiocyanate Method}

This procedure may have certain advantages in the presence of elements which require a non-aqueous medium to develop any appreciable color. Such elements are $\mathrm{Ti}(\mathrm{IV}), \mathrm{Nb}(\mathrm{V}), \mathrm{Co}(\mathrm{II})$, and $\mathrm{V}$ (III). The reduction again was the same as in (I). Five ml. of 3.0 molar ammonium thiocyanate aqueous solution were added, and the solution was diluted with water to $25 \mathrm{ml}$. The color development was rapid, and the absorbance may be obtained im mediately upon mixing. The molar absorbance index is 13,800 at the $398 \mathrm{~m} \mu$ peak.

VIII. Discussion

The spectra of $W(V I)$ and $M o(V I)$ in the thiocyanate acetone medium are quite different and in certain applications may be analytically useful. Figure 12 shows the Mo(VI) thiocyanate complex in acetone medium. No absorbance was observed for $W(V I)$ above $330 \mathrm{~m} \mu$. The acetone thiocyanate medium below $330 \mathrm{~m} \mu$ masks any absorbance in the ultra violet region. The molybdenum and tungsten can be oxidized to the +6 valence state by bromine. The excess bromine may be boiled off, although bromine did not form any colored products in the acetone thiocyanate medium.

A feature of the cuprous chloride reduction of molybdenum was the elimination of tungsten interference. Cuprous chloride did not reduce W(VI) to $W(V)$. Table I shows the limits of tungsten concentration which may be tolerated. Since Mo(III) forms virtually no color in the thiocyanate acetone medium, reduction with $\mathrm{Sn}$ (II) or mercury in strong hydrochloric acid eliminates molybdenum interference in the tungsten analysis. 


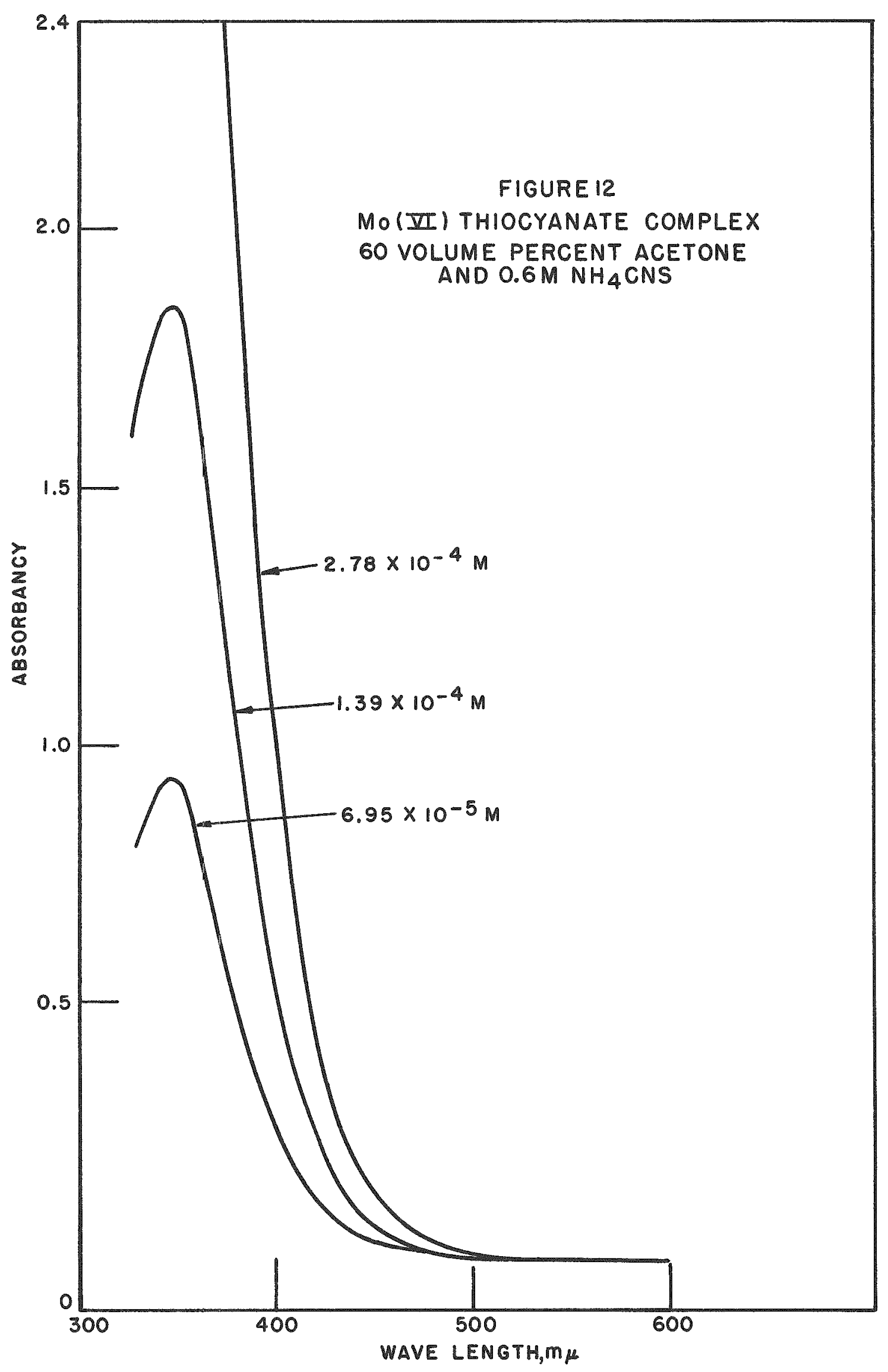


EFFECTS OF FOREIGN CATIONS ON THE MO(V) AND W(V) SPECTROPHOTOMETRIC ANALYSIS IN ACETONE THIOCYANATE MEDIUM

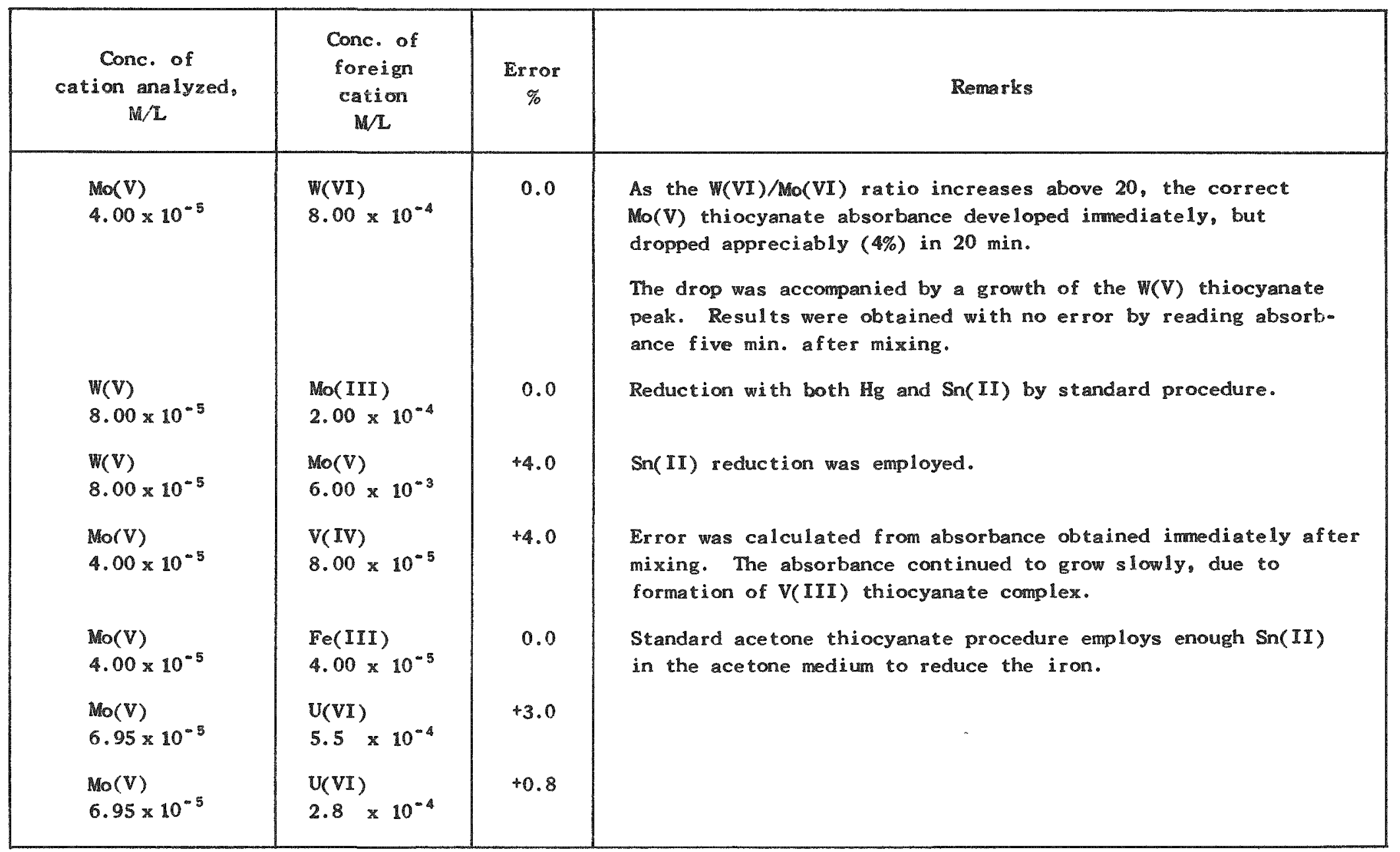


Iron is a major source of difficulty in obtaining a stable color with Mo(V) thiocyanate. Even when scanning the $460 \mathrm{~m} \mu \mathrm{Mo}(\mathrm{V})$ thiocyanate peak, iron interference appears as a small broadening of the peak. Thus a $30 \%$ increase in the $460 \mathrm{m \mu}$ peak due to $\mathrm{Fe}(\mathrm{III})$ thiocyanate increased the resolution of the Mo(v) thiocyanate $460 \mathrm{~m} \mu$ peak only $2 \%$, from $13 \%$ to $15 \%$. If a large excess of $\mathrm{Sn}(\mathrm{II})$ is added to reduce the iron, the Mo(V) thiocyanate complex is relatively unstable. Figure 13 shows the complex nature of reactions involved. In the absence of iron, the standard procedure A for molybdenum is applied, as shown in curve 3 of Figure 13, except for the quantity of $\mathrm{Sn}$ (II) added, which was increased to $1.0 \mathrm{ml}$. of $10 \%$ by weight $\mathrm{Sn}$ (II) solution. The absorbance measured was immediately below the known correct value of 1.29. The curves of Figure 13 were obtained with the Cary recording spectrophotometer, which allows the accurate measurement of the high absorbance values. It will be noted that in curve 3 , copper was employed to reduce the Mo(VI) to $\mathrm{Mo}(\mathrm{V})$ and the $\mathrm{Sn}$ (II) was added after the thiocyanate acetone. In curve 2 , the same color development procedure was applied with $1.0 \mathrm{ml}$. of $10 \% \mathrm{Sn}(\mathrm{II})$, but in the presence of $4.16 \times 10^{-4} \mathrm{MFe}$ (III), which was added to the original Mo(VI) standard.

Curve 1 is the same reaction with the Cu(I) deleted from procedure $A$ and with the same concentration of $F$ (III). The presence of iron prevented the rapid over-reduction of $\mathrm{Mo}(\mathrm{VI})$ to $\mathrm{Mo}$ (III) as shown in Curve 3 , and the absence of copper apparently slowed the reaction between $\mathrm{Sn}$ (II) and $\mathrm{Fe}$ (III) in the acetone medium. The procedure employed in Curve 2 is thus recommended in cases where excess iron is present. However, the reaction rates of the solutions may be sensitive to other impurities, and the analyst must exercise care in applying the procedure. For precise results, the separation of large quantities of iron from molybdenum should be made. In this laboratory, the separation of 10,000 to 1 ratios of $\mathrm{Fe}$ (III)/Mo(VI) were made with a Dowex 50, 100 mesh, $7.2 \%$ cross linked resin, $1 / 2$ in. diameter by $2-1 / 2$ in. cylindrical column. The Fe(III) and Mo(VI) mixture was first passed through a pH 2 equilibrated column as a dilute $\sim 0.5$ M hydrochloric acid solution and the Mo(VI) eluted with $75 \mathrm{ml}$. of $0.04 \mathrm{M}$ ammonium thiocyanate. The eluted solution of Mo(VI) was reduced to $0.50 \mathrm{ml}$. of concentrated sulfuric acid, and the color was developed by procedure $A$.

\section{Summary}

Previous difficulties in the development of the maximum and stable $M o(V)$ thiocyanate and $W(V)$ thiocyanate absorbances have been critically examined and corrected. The molar absorbance index in the acetone thiocyanate medium employed is $18,700 \pm 150$ at $460 \mathrm{~m} \mu$ for $\mathrm{Mo}(\mathrm{V})$ and $17,600 \pm 130$ at $398 \mathrm{~m} \mu$ for $W(V)$. The absorbances in the acetone medium of the other stable valence states of tungsten and molybdenum have been reported. 
FIGURE 13

$--6.95 \times 10^{-5} \mathrm{M}$ MO(III) STANDARD THIOCYANATE ACETONE PROCEDURE A, NO IRON PRESENT

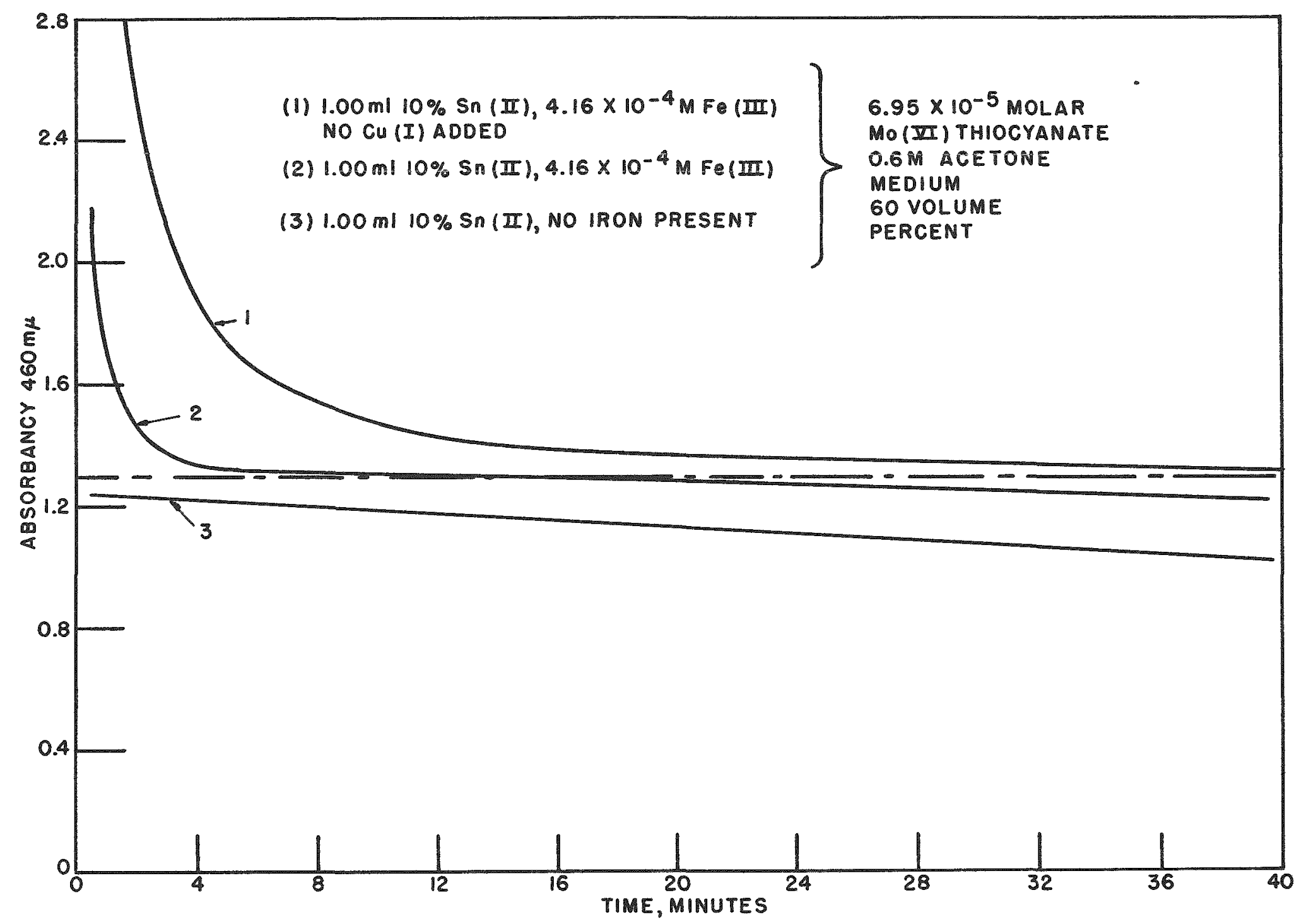


Bibliography

1. Vogel, H. W., Ber., $8,1533,(1875)$

2. Ossian, Pharm. Centr., 13, 205, (1837)

3. Tatlock, R. R., J. Soc. Chem. Ind., 6, 279, (1887)

4. Crouthamel, C. E. and Johnson, C. E., Anal. Chem., 24, 1780, (1952)

5. Hillebrand, W. F., Lundell, G. E. F., Bright, H. A., and Hoffman, J. E., Applied Inorganic Analysis

6. Braun, A. D., Z, Anal. Chem., $\underline{2}, 36,(1863)$

7. King, W. J., Ind. Eng. Chem., 15, 373, (1923)

8. Kapron, M. and Hehman, P. L., Ind. Eng. Chem., anal. ed., 17, 573, (1945)

9. Dick, A. T. and Bingley, J. B., Nature, 158, 516, (1946)

10. Birnbaum, N. and Walden, G. H., J. Am. Chem. Soc., 60, 64, (1938)

11. Geld, I. and Carroll, J., Anal. Chem., 21, 1098, (1949)

12. Freund, H., Wright, L. M., Brookshier, R. K., Anal. Chem., 23, 781, (1951)

13. Gentry, C. H. R. and Sherrington, L. G., Analyst, 73, 57, (1948)

14. Lauw-Secha, Lord, S. S., Hume, D. H., Anal. Chem., 24, 1169, (1952)

15. Freund, H. and Levitt, A. E., Anal. Chem., 23, 1813, (1951) 